\title{
The purposes of interpersonal communication: A survey to find the most likely general reasons why people engage in communication
}

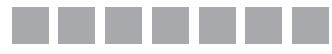

Mikael Jensen

UNIVERSITY OF GOTHENBURG, SWEDEN

DOI: $10.19195 / 1899-5101.11 .1(20) .2$

\begin{abstract}
The purpose underlying this paper is to find out what purposes/functions people from a diverse background assess to be more important and central to human interpersonal communication. A list of 17 possible purposes and functions of interpersonal communication was derived from a literature review and used in a survey study. The questionnaire was filled out by 313 participants (international students being in Sweden) from diverse cultural backgrounds. The findings from this study suggest that the participants acknowledge very central aspects of human life to be the reason for communicating. The most agreed upon reasons why we communicate is to share and enhance enjoyment (share positive emotions) and to create and strengthen social bonds (manage relationships).
\end{abstract}

KEYWORDS: purpose, interpersonal communication, emotion, cognition, relationships, joint activity.

\section{INTRODUCTION}

It has been suggested in definitions of communication (e.g. Allwood, 2002) and as part of communication theories (e.g. Mangion, 2011; Krcmar, Ewoldsen \& Koerner, 2016) that communication as such has a purpose or a function. When we think about it, why else would we communicate? On a very abstract level, Allwood (2002) is assuming that the purpose of communication can be physical, biological, psychological, or social. On a more concrete level the purpose of communication can be to make a claim or obtain certain information.

It is relatively well studied how we communicate, through what channels we communicate, how the type of relationship affects communication (that is with who/whom we communicate), and also what we communicate about. Another fundamental question is why we communicate. This is less studied. We can find the why on several levels. On a wide and fundamental level we communicate to survive 
or we communicate to share information. On a specific level we communicate to attain a certain goal: "Can you pass me the salt, please?" On an intermediate level there might be purposes that are recognized in many situations but still rather concrete. Examples of this can be that we communicate to develop a relationship or to share our recent experiences.

The purpose underlying this paper is to find out what purposes people from a diverse background assess to be more important and central to human interpersonal communication. To be able to do any kind of generalizations about the results from this study the sample is deliberately diverse. If people from different cultures agree to some extent the outcome might be more solid. Since there are no specific assumptions about why we communicate with each other or any specific hypotheses to be tested the study is guided by the following research question.

RQ: Why, in general terms, do humans engage in interpersonal communication? What statements, about the purpose of communication, are ranked as the most likely reasons behind interpersonal communication?

This is done by identifying several potential communication purposes, having participants fill out a questionnaire to assess the purposes and doing a statistical analysis of the outcome. The identification process is based on a literature review presented below. After that the method and results are presented. Finally, a discussion about the result and a conclusion ends the paper. The study is limited to interpersonal communication but it is most probable that the same purposes are relevant in group communication and other kinds of communication.

\section{LITERATURE REVIEW: PURPOSE AND FUNCTION OF COMMUNICATION}

A diverse list of possible purposes are collected from existing communication theories and models. The list is not exhaustive and the proposals are not mutually exclusive. Some can be said to be a special case of another purpose. Instead of an exhaustive list the strategy is to test a diverse collection of purposes. An exhaustive list would be too vast. Instead of mutually exclusive proposals, the different degrees of specificity are also tested.

As a starting point we can look at the five main functions suggested by $\mathrm{Krcmar}$, Ewoldsen and Koerner (2016). We communicate to: 1) exchange information, 2) create, develop and maintain interpersonal relationships, 3) influence others, 4) define and give meaning to persons' experiences, 5) Create a shared social reality for self and other. It is most probable that there are more functions. They only cover the perspectives of a few theoretical traditions (see Craig \& Muller, 2007). Thus the list will be enhanced. The last two functions are a bit difficult to express in layman's terms. They will not be presented in that way.

Communication theories within the cybernetic tradition and of a similar kind emphasize the necessity of information. Communication is not possible without information. Scholars like Shannon and Weaver (1949), Ruesch and Bateson (1951), 
Rogers (2003), and Allwood (2008) all include information in their definitions of communication or in their communication models. To claim that we share information is primarily about what we communicate or how we communicate. Not necessarily why we communicate. In layman's terms, on the other hand, we could say that we lack certain information and to communicate with someone that has that certain information would be a reasonable purpose (cf. Berger \& Calabrese, 1975). From a system perspective the system would break down, eventually, without information. If we do not want a system breakdown, sharing of information can be seen as a function or purpose. It is therefore reasonable to assume the following purpose:

\section{A. The purpose of communication is to share information}

Communication theories and models involve relationships of different degrees (Miller, 2002; Allen et al. 2008; Littlejohn \& Foss, 2008; Eadie \& Goret, 2013; West \& Turner, 2014; Braithwaite \& Schrodt, 2015). To get to know someone or to become an acquaintance or a friend we have to communicate. It has been suggested that the more we communicate the better we get to know that other person (Altman \& Taylor, 1973; Berger \& Calabrese, 1975; Mongeau \& Miller Henningsen, 2008; Knapp $\&$ Vangelisti, 2009). There are good reasons to claim that human beings are socially oriented and that we need to communicate with others and create social bonds (Jensen, 2016). We thus assume the following purpose:

\section{B. The purpose of communication is to create and strengthen social bonds}

The study of persuasion, as the core of rhetoric, is one of the oldest aspects of communication studies (Craig \& Muller, 2007; Shen, 2013). It can be discussed whether persuasion can be a purpose in itself or if it is used for some other purpose. From this tradition, anyway, comes the idea that we communicate to influence others (Krcmar, Ewoldsen \& Koerner, 2016). It is here assumed that:

\section{The purpose of communication is to affect and influence others}

Emotions and emotional expressions have been studied for decades among communication scholars and in closely-linked disciplines. Emotions are acknowledged as a great part of human everyday life (Planalp, 2001) and especially important to our relationships (Floyd, Judd \& Hesse, 2008; Metts \& Planalp, 2011). The problem is that emotional experience is different from emotional expressions (Andersen \& Guerrero, 1998; Matsumoto \& Hwang, 2013). Emotional experiences are what we experience inside in a very private sense while emotional expressions are what we show others by means of words, voice characteristics, facial expressions, stance and gestures. For personal, relational, situational or cultural reasons we can try to avoid expressing what we truly feel (Floyd, 2006; Matsumoto \& Hwang, 2013). If we want to communicate emotions it is more reasonable to claim that we deliberately share emotional expressions than to share emotional experiences. 
$D$. The purpose of communication is to express emotions

Human beings are unique in the sense that we instruct individuals close to us to give support of some kind (Tomasello, 2003). We are the only species that teach each other in organized ways. We can also see this tendency in children. Halliday (1978) calls this the informative function. Children have an interest in transmitting (new) information to others that do not yet have this information. We can therefore assume that we communicate to inform others.

\section{E. The purpose of communication is to inform others}

Sometimes we realize that we do not have information that we for some reason need, perhaps in order to learn something. That will motivate us into information seeking behavior (Berger \& Calabrese, 1975; Afifi \& Weiner, 2004; Afifi, 2010; Knobloch, 2008; Gottlieb, Oudeyer, Lopes \& Baranes, 2013; Jensen, 2016). We might also want to hear the latest news about what has happened in a friend's life, in our network or in our society.

\section{F. The purpose of communication is to become informed}

Generally we dislike disorder but we may engage with it for different reasons and manage the disorder in different ways. Some may want to create order by regulating other individuals' behavior (Mangion, 2011), some by organizing people as a unit (Miller, 2015) and some want to organize information (Salem, 2009). In layman's terms it would be said that:

\section{G. The purpose of communication is to make sure that everything is in order}

It is said that the human is a cooperative species (Tomasello, 2008; 2009). To be able to cooperate she needs to communicate. The next step is to coordinate communication and acts (Deutsch, 1973; Allwood, 2007). A more complex level is to collaborate, meaning to be involved in a joint activity without a joint goal but rather to follow certain rules that regulate the activity (Allen \& Plax, 1999). Finally, cooperation is to have a joint goal (Deutsch, 1973; Tomasello, 2009; Paternotte, 2014) and to show ethical concern for the other(s) (Allwood, 2007). Therefore it is probable that we communicate to be able to carry out joint activities.

H. The purpose of communication is to coordinate, collaborate, and/or to cooperate

It is reasonable that people may want to feel satisfaction when communicating or after a conversation (Solomon \& Theiss, 2013). It may be less satisfying if the other person is sad or feels stress. Just as a parent tries to calm an upset child, we have a tendency to do that with our peers as well.

\section{The purpose of communication is to keep others calm and satisfied}

Impression management is about presenting oneself to others (Goffman, 1959; Burgoon, Buller \& Woodall, 1996). "Here I am", “This is who I am" or "This is who 
I want to be" (cf. Halliday, 1978; Fiske \& Taylor, 2014). Impression management is a kind of negotiation with oneself as well as with others (Goffman, 1959; Knapp \& Vangelisti, 2009). Some individuals are more adaptable while others find it important to show their independence and personal style.

\section{J. The purpose of communication is to show who I am (self-presentation)}

Davis (1973) has suggested four reasons why people get together. This can influence why we initiate relationships and why we communicate. He calls them impulses: the impulse of receiving stimulation, the impulse to express experience, the impulse to assert oneself, the impulse to enhance enjoyment. When we are bored we want stimulation. Some prefer social stimulation (McCrae \& Costa, 2006) while others want intellectual stimulation (Furnham, 2008). In both cases it could mean that we engage in conversations. This leads to a possible purpose of communication.

\section{$K$. The purpose of communication is to be stimulated}

Humans are storytellers (Bruner, 2003; Koenig Kellas, 2008; Boyd, 2009). The stories can be short and about everyday events or long and complex about real adventures. In both cases it is important to us to have someone to share these stories about own experiences with (Knapp \& Vangelisti, 2009; Krcmar, Ewoldsen \& Koerner, 2016). Davis' second impulse can easily be phrased into a communication purpose.

\section{The purpose of communication is to share own experiences}

The impulse to assert oneself is close to the self-presentation purpose and is therefore left out in this case. The impulse to enhance enjoyment is not yet covered. It has been suggested several times that it is hard to be festive alone. If something positive has happened, we want to share it. When we are together with friends and family we easily share happiness (Planalp, 2001; Knapp \& Vangelisti, 2009).

\section{The purpose of communication is to share and increase enjoyment}

People may find themselves in a situation where they feel insecure or have low self-esteem. Since it is an unpleasant feeling, we would want to get out of this state. This can be done through avoiding stressful topics (Afifi \& Matsunaga, 2008), trying to assert oneself (Knapp \& Vangelisti, 2009) or being self-pitying and hoping that others will try to state the opposite or give comfort.

\section{$N$. The purpose of communication is to feel less insecure about oneself}

Salem (2009) explains that uncertainty is doubt. Doubt is unpleasant and something that we want to get rid of (Peirce, 1992). According to Salem, doubt has appeared because the information available does not match the information needed in a particular situation. Because of that we might, for example, engage in information seeking behavior and ask people to gain information. Berger and Calabrese (1975) developed a theory around the concept of uncertainty and others followed 
(Knobloch, 2008). The idea that we typically want to reduce uncertainty has been questioned. We might want to manage the uncertainty in other ways than just reduction (Afifi \& Matsunaga, 2008).

\section{$O$. The purpose of communication is to reduce or manage uncertainty}

Communication is mentioned in many theories to be intentional. What we communicate is not pure meaning but intentions (Krauss \& Morsella, 2014). The intentions give a clue about what we mean when we communicate. This idea has been central to communication theories since Grice (1957) presented it and is defended by Searle (1969), Sperber \& Wilson (1995), Gibbs (1999; 2001), Tomasello (2005; 2008), Matsumoto (2010) and Jensen (2016). Does this mean that the purpose of communication is the intention? It might be to share intentions since it is equally important to have an intention behind what is communicated as it is to be able to read the other person's communicated intention.

\section{P. The purpose of communication is to share intentions}

In some cultures/situations people are encouraged to be spontaneous while in other cultures/situations people are expected to inhibit thoughts and feelings (cf. de Mooij, 2013). It can be a bit problematic to state that the purpose of communication is to inhibit thoughts and feelings. It is easier to say that the purpose is to communicate in a spontaneous way. This is in line with the authenticity that is embraced by the phenomenological tradition (Craig \& Muller, 2007), which is to be true to oneself. It leads to the last suggested purpose:

Q. The purpose of communication is to share what is on one's mind (thoughts and feelings) at the moment

It is very much like thinking out loud. Unfiltered thoughts.

\section{METHODS}

The study is based on a survey. It is designed to make it possible for the participants to agree on a number of statements about why we communicate, that in turn can be ranked.

Participants: 313 students participated in the study. They were enlisted in international courses and programs at two Swedish universities during the Autumn Term 2014. More than ten cultures are represented by at least ten individuals and the rest of the participants come from a variety of cultures. The four largest culture groups (Brazil, China, Sweden, and Germany) are represented by 25 to 50 participants each. A little less than one third of the participants are males. The age of the participants ranges from 18 to 44 . The average age is 25 years. The questionnaire was handed out during a course introduction. Participation was voluntary but only a handful of people abstained from or aborted their participation. 
The questionnaire: The questionnaire is paper-based. It covers background information like gender, age, culture, and language. The main part is based on 17 statements about communication (see literature review above) from an individual perspective. The statements always start with an "I". A seven choice Likert scale was used. On the one end the option was "fully agree", "agree", "slightly agree", "neutral", "slightly disagree", "disagree", and on the other end "fully disagree".

The main section started with an introduction about purposes of communication and instruction to think about communication in more general terms than a specific occasion. After every statement there was also a short clarifying text to avoid misinterpretations.

313 participants handed in the questionnaire but seven were incomplete. The analysis is based on 306 questionnaires.

The data analysis: The options in the questionnaire were coded. "Fully agree" had the numeric value of 1 and "Fully disagree" had the numeric value of 7 . The average value as well as the standard deviation for each statement was calculated. A one way ANOVA was conducted and a t-test comparing every statement average with every other statement average was conducted.

\section{RESULTS}

The result of the survey can be seen in table 1 . The statements are listed in the ranking order. A lower mean stands for a higher agreement among the participants.

A one way ANOVA shows that there are differences between the mean values $(\mathrm{F}=36.33 ; \mathrm{p}<0.001)$. T-tests were conducted to test the differences between each mean value in relation to every other mean value. The mean value of the first ranked purpose is significantly $(\mathrm{p}<0.05)$ different from all other purposes except number 2 . The same is true for purpose number 2 on the list. It is significantly $(\mathrm{p}<0.05)$ different from all other purposes except number 1 . Number 1 and 2 cannot be separated from each other but they are separated from the rest, suggesting that there are two cases that the participants in this study say are more typical in their interpersonal communication. The participants in this study communicate to share and increase enjoyment (86.3 percent of the participants slightly agree, agree or fully agree while 2.9 percent slightly disagree, disagree, or fully disagree) and they communicate to create and strengthen social bonds (86.3 percent of the participants slightly agree, agree, or fully agree while 2.9 percent slightly disagree, disagree, or fully disagree). Having fun together and managing relationships is why people communicate in many situations. The purpose ranked as number 3 is significantly $(\mathrm{p}<0.05)$ different from all the other purposes except for numbers 4 and 5 . This means that number 3 cannot be ranked higher than position 3 and not lower than 5 . A top five purpose, it can be concluded, is to communicate to become informed.

The purpose ranked as number 4 has a mean value that is significantly $(\mathrm{p}<0.05)$ different from all other mean values except for number 3 , number 5 and number 6 . 
Table 1. The ranking of the purposes based on mean values

\begin{tabular}{|l|r|r|r|}
\hline \multicolumn{1}{|c|}{ PURPOSE (RANKING) } & $\begin{array}{c}\text { POSSIBLE } \\
\text { RANGE }\end{array}$ & MEAN & STDV \\
\hline 1. To share and increase enjoyment & Position 1-2 & 2.144 & 1.162 \\
\hline 2. To create and strengthen social bonds & Position 1-2 & 2.190 & 1.138 \\
\hline 3. To become informed & Position 3-5 & 2.403 & 1.312 \\
\hline 4. To coordinate, collaborate and/or cooperate & Position 3-6 & 2.466 & 1.426 \\
\hline 5. To share experiences & Position 3-6 & 2.472 & 1.241 \\
\hline 6. To share information & Position 4-7 & 2.616 & 1.489 \\
\hline 7. To think out loud (what's on my mind at the moment) & Position 6-11 & 2.744 & 1.495 \\
\hline 8. To express emotions & Position 7-13 & 2.869 & 1.588 \\
\hline 9. To make sure that everything is in order & Position 7-13 & 2.879 & 1.469 \\
\hline 10. To inform others & Position 7-13 & 2.889 & 1.502 \\
\hline 11. To share intentions & Position 7-13 & 2.961 & 1.295 \\
\hline 12. To keep others calm and satisfied & Position 8-14 & 3.000 & 1.541 \\
\hline 13. To reduce or manage uncertainty & Position 8-14 & 3.026 & 1.428 \\
\hline 14. To show who I am (self-presentation) & Position 12-15 & 3.213 & 1.586 \\
\hline 15. To be stimulated & Position 14-16 & 3.344 & 1.569 \\
\hline 16. To influence others & Position 15-16 & 3.489 & 1.677 \\
\hline 17. To feel less insecure about myself & Position 17 & 4.193 & 1.883 \\
\hline
\end{tabular}

Source: Author.

This means that number 4 on the list cannot be ranked higher than number 3 and not lower than number 6 . The purpose ranked as number 5 has a mean value that is significantly $(\mathrm{p}<0.05)$ different from all other mean values except for numbers 3,4 , and 6 . This purpose cannot be ranked higher than number 3 and not lower than number 6 . The purpose ranked as number 6 on the list is significantly $(\mathrm{p}<0.05)$ different from other mean values except for numbers 4,5 and 7 . This means that purpose number 6 cannot be ranked higher than position 4 and not lower than position 7 .

These six alternatives are the only ones in this study, according to the participants' choices, that can reach the top five of communication purposes. The first five are the only ones that can reach the top three.

The lowest ranked purpose is to communicate to feel less insecure about oneself. It is significantly $(\mathrm{p}<0.05)$ different from all other mean values. The mean value suggests that it is a neutral purpose and slightly towards the negative side. 28 percent of the participants disagree or fully disagree that this would be a purpose to communicate. On the other hand, 22 percent agree or fully agree that this would be a purpose to communicate. It is thus not unlikely, at least for some individuals, to sometimes communicate to reduce or manage the feeling of insecurity. 
Three of the statements are wider than the rest. They are found in positions 6 (4-7), 8 (7-13) and 11 (7-13). We communicate to share information, to express emotions and to share intentions. According to some theories we do this all the time. The participants seem to think that these purposes are relevant but not specific enough to be recognized as typical.

\section{DISCUSSION}

There are five purposes in this study that are likely to reach a top three position. Two of them stand out on the absolute top while three more at best can reach position three. What can be assumed about these five purposes? Two of the purposes can be found in Davis' (1973) reasons for getting together. We communicate to share experiences and we communicate to share or increase enjoyment. Let us start with number one on the list. To share and increase enjoyment is about emotions. First it means that it is a special case of expressing emotions (number eight on the list). Second, enjoyment is widely accepted and recognized as a positive emotion. In most cultures and in most situations it is more accepted and even expected to express and share positive emotions. In several cultures and situations negative emotions like anger, disgust, sorrow, or fear are supposed to be inhibited to not lose face (Argyle, 1988; Andersen \& Guerrero, 1998). It may even be the case that an experience of a negative emotion is expressed (masked) by a positive one. It can therefore be understood that a larger number of participants in the present study assessed the sharing and increasing of enjoyment as a more important purpose of communication than the wider and more including statement of expressing emotions since that would also include expressing negative emotions that sometimes are avoided and thus are not an embraced purpose to communicate. For politeness reasons we usually greet both strangers and close friends with a smile (Knapp \& Hall, 2006; Jensen, 2015) but very seldom with a negative emotional expression.

Storytelling is widely recognized as something that humans do to cognitively structure events both for the sender and the receiver (Norman, 1982; Egan, 1986; Bruner, 1990; Schank, 1999; Herman, 2003; Goodson, Biesta, Tedder \& Adair, 2010). It is also a widely used way to share gossip and news (Norman, 1993; Bruner, 2003; Boyd, 2009). Telling stories is one of the unique aspects of human cognition and communication. With this in mind it makes sense that the participants in the study find the sharing of own experiences important as a purpose of communication. Sharing of experiences, whether simple or complex, is structured as a story. The statement is not just aspiring to the top three position but also has the third lowest standard deviation, suggesting that there is a high agreement among the participants (see table 1). The receiver side of it is to listen to others' experiences and instructions to become informed. Human beings are not just storytellers but are also willing to give instructions (Tomasello, 2003). If others do not share experiences or give instructions we tend to ask questions to become informed or ask 
questions to increase clarity of what has just been said (Berger \& Calabrese, 1975; Afifi \& Weiner, 2004; Afifi, 2010; Knobloch, 2008). This is something that starts very early in childhood (Harris, 2012). To communicate to gain information and knowledge is thus a very reasonable purpose.

For practical reasons we need to communicate to manage joint activities (Deutsch, 1973; Argyle, 1990; Tomasello, 2009). We need to coordinate individuals and their acts to function as a unit. Joint activities are not just about communication and coordination. When it fully functions it makes us reach joint goals (Paternotte, 2014). Since we are socially oriented beings (Jensen, 2016) it is probable that we will try to achieve goals together or at least try to manage joint activities. The purpose to communicate to coordinate, collaborate and/or cooperate is crucial to success. Another aspect of us being socially oriented becomes obvious in the way we manage relationships. Needless to say, relationships are very important to us all but they are also tightly intertwined with our communication (Ruesch \& Bateson, 1951; Watzlawick, Beavin Bavelas \& Jackson, 1967; Guerrero, 2008; Mongeau \& Miller Henningsen, 2008; Knapp \& Vangelisti, 2009; Krcmar, Ewoldsen \& Koerner, 2016). The purpose to communicate to create and strengthen social bonds is a natural aspect of our sociability.

On an analytical level we can assume that human communication involves sharing and expressing emotions, sharing and expressing thoughts (cognition) and managing relationships and managing joint activities as a more social side. These are well-acknowledged aspects of human life. This is also what is reflected in this study. We do communicate to express emotions, positive emotions like joy in particular. We do communicate to share thoughts, especially when we share experiences on the sender side and when we communicate to become informed (and gain knowledge) on the receiver side. We do communicate to fully function as social beings and we especially do that when we manage our relationships and when we manage joint activities.

When we now look at the results, the question is whether the participants have based their assessments on folk psychology and folk sociology or if they have based it on personal experiences and personal beliefs. Folk psychology and especially folk sociology is probably affected by cultural differences and that would certainly have led to a more diverse outcome. The fact that very few disagreed on the two top statements suggests that most of the participants have encountered everyday events where communication serves the purpose of sharing enjoyment and managing relationships. This is further supported by the lowest standard deviation for these two statements (see table 1). The whole group of participants has a high level of agreement. The use of the "I"-form in the questionnaire statements makes it easier for the participant to relate it to personal experiences instead of general or abstract reasoning.

General and abstract aspects are also related to the assessments of the statements. The three most abstract and general statements never reached a potential 
top three position even though they are the most inclusive. On an analytical level most participants can relate to communication as sharing information, expressing emotions and sharing intentions. Even so, these purposes do not seem concrete enough to relate to everyday situations that involve typical communication. The widest purpose is not recognized as the most probable purpose.

The culturally diverse sample can be seen both as a strength and a weakness. The weakness is mainly that people have different communication patterns and may understand the statements in different ways. In a comparison between the four largest groups the two top-ranked statements show small differences but not big enough to be significant in a t-test. The participants from these four groups (China, Germany, Sweden and Brazil) assess the two top-ranked statements in similar ways. This is strengthening the outcome of the study. The three following statements differ significantly between at least two cultural groups.

One obvious limitation of this study is the missing purpose about acquiring resources. It is likely that most participants would agree that we communicate to gain some kind of resource in a more concrete sense than to acquire information/ knowledge. We communicate to get money, to get food and to get shelter. Some would also argue that we communicate to get affection (Floyd, 2006; Knapp \& Vangelisti, 2009). To communicate to create a shared social reality (Krcmar, Ewoldsen \& Koerner, 2016) would be relevant if it could be put in layman's terms. These aspects need to be included in future studies.

\section{CONCLUSION}

The findings from this study suggest that the participants acknowledge very central aspects of human life to be the reason for communicating. We communicate, as an aspect of our emotions, to share and increase enjoyment. We communicate, as an aspect of our social orientation, to manage relationships and joint activities. We communicate, as an aspect of our cognition, to share experiences and to become informed (about news and gain knowledge). The results also indicate that we gather around mid-level purposes that are not too abstract and therefore can be related to well-known everyday experiences. This is most emphasized by the two first purposes on the ranking list: to share and increase enjoyment and to create and develop relationships.

\section{REFERENCES}

Afifi, W. A. (2010). Uncertainty and information management in interpersonal contexts. In: Smith, S. W., \& Wilson, S. R. (eds.), New Directions in Interpersonal Communication Research. London: SAGE. http://dx.doi.org/10.4135/9781483349619.n5.

Afifi, W. A., \& Matsunaga, M. (2008). Uncertainty management theories. In: Baxter, L. A. \& Braithwaite, D. O. (eds.), Engaging Theories in Interpersonal Communication. Multiple Perspectives. London: SAGE. 
Afifi, W. A., \& Weiner, J. L. (2004). Toward a theory of motivated information management. Communication Theory, 14, pp. 167-190. http://dx.doi.org/10.1111/j.1468-2885.2004.tb00310.x.

Allen, M., Preiss, R. W., Gayle, B. M., \& Burrell, N. (eds.) (2008). Interpersonal Communication Research. Advances Through Meta-Analysis. New York: Routledge.

Allen, T. H., \& Plax, T. G. (1999). Group communication in the formal educational context. In: Frey, L. R. (eds.), The Handbook of Group Communication Theory and Research. London: SAGE.

Allwood, J. (2002). Bodily communication dimensions of expression and content. In: Granström, B., House, D., \& Karlsson, I. (eds.), Multimodality in Language and Speech Systems. London: Kluwer Academic Publisher.

Allwood, J. (2007). Cooperation, competition, conflict and communication. Gothenburg Papers in Theoretical Linguistics. Gothenburg: University of Gothenburg.

Allwood, J. (2008). A Typology of Embodied Communication. In: Wachmuth, I., Lenzen, M., \& Knoblich, G. (eds.), Embodied Communication in Humans and Machines. Oxford: Oxford University Press.

Altman, I., \& Taylor, D. A. (1973). Social Penetration: The Development of Interpersonal Relationships. New York: Holt, Rinehart \& Winston.

Andersen, P. A., \& Guerrero, L. K. (1998). Principles of communication and emotion in social interaction. In: Andersen, P. A. \& Guerrero, L. K. (eds.), The Handbook of Communication and Emotion: Research, Theory, Applications and Contexts. San Diego, CA: Academic Press.

Argyle, M. (1988). Bodily Communication. New York: Methuen \& Co.

Argyle, M. (1991). Cooperation. The Basis of Sociability. London: Routledge.

Berger, C. R., \& Calabrese, R. J. (1975). Some explorations in initial interaction and beyond: toward a developmental theory of interpersonal communication. Human Communication Theory, 1, pp. 99-112. http://dx.doi.org/10.1111/j.1468-2958.1975.tb00258.x.

Boyd, B. (2009). On the Origin of Stories. Evolution, Cognition and Fiction. Cambridge, MA: The Belknap Press of Harvard University Press.

Braithwaite, D.O., \& Schrodt, P. (eds.) (2015). Engaging Theories in Interpersonal Communication: Multiple Perspectives. London: SAGE.

Bruner, J. (1990). Acts of Meaning. Cambridge, MA: Harvard University Press.

Bruner, J. (2003). Making Stories. Law, Literature, Life. Cambridge, MA: Harvard University Press.

Burgoon, J. K., Buller, D. B., \& Woodall, W. G. (1996). Nonverbal Communication. The Unspoken Dialogue. New York: The McGraw-Hill companies.

Craig, R. T., \& Muller, H. L. (eds.) (2007). Theorizing Communication. Readings Across Traditions. London: SAGE.

Davis, M. S. (1973). Intimate Relations. New York: Free Press.

de Mooij, M. (2014). Human and Mediated Communication around the World: A Comprehensive Review and Analysis. Dordrecht: Springer.

Deutsch, M. (1973). The Resolution of Conflict: Constructive and Destructive Processes. New Haven: Yale University Press.

Eadie, W. F., \& Goret, R. (2013). Theories and models of communication: Foundations and heritage. In: Cobley, P. \& Schulz, P. J. (eds.), Theories and Models of Communication. Berlin: De Gruyter Mouton.

Egan, K. (1986). Teaching as Storytelling. Chicago: The University of Chicago Press.

Floyd, K. (2006). Communicating Affection. Interpersonal Behavior and Social Context. New York: Cambridge University Press.

Floyd, K., Judd, J., \& Hesse, C. (2008). Affection exchange theory. In: Baxter, L. A., \& Braithwaite, D. O. (eds.), Engaging Theories in Interpersonal Communication. Multiple Perspectives. London: SAGE.

Furnham, A. (2008). Personality and Intelligence at Work. East Sussex, UK: Routledge.

Gibbs, R. W. (1999). Intentions in the Experience of Meaning. New York: Cambridge University Press. 
Gibbs, R. W. (2001). Intentions as emergent products of social interactions. In: Malle, B. F., Moses, L. J., \& Baldwin, D. A. (eds.), Intentions and Intentionality. Foundations of Social Cognition. Cambridge, MA: A Bradford Book.

Goffman, E. (1959). The Presentation of Self in Everyday Life. New York: Anchor books.

Goodson, I. F., Biesta, G. J. J., Tedder, M., \& Adair, N. (2010). Narrative Learning. Oxon, UK: Routledge.

Gottlieb, J., Oudeyer, P. Y., Lopes, M., \& Baranes, A. (2013). Information-seeking, curiosity, and attention: Computational and neural mechanisms. Trends in Cognitive Sciences, 17(11), pp. 585593. http://dx.doi.org/10.1016/j.tics.2013.09.001.

Grice, H. P. (1957). Meaning. The Philosophical Review, 66(3), pp. 377-388. http://dx.doi.org/10. $2307 / 2182440$.

Guerrero, L. K. (2008). Attachment theory. In: Baxter, L. A., \& Braithwaite, D. O. (eds.), Engaging Theories in Interpersonal Communication. Multiple Perspectives. London: SAGE.

Halliday, M. A. K. (1978). Language as Social Semiotic: The Social Interpretation of Language and Meaning. London: Edward Arnold.

Harris, P. L. (2012). Trusting What You're Told. How Children Learn From Others. London: The Belknap Press of Harvard University Press.

Herman, D. (ed.) (2003). Narrative Theory and The Cognitive Sciences. Stanford, CA: CSLI Publications.

Jensen, M. (2015). Smile as feedback expressions in interpersonal interaction. International Journal of Psychological Studies, 7(4), pp. 95-105.

Jensen, M. (2016). Touchpoint management and interpersonal communication. Studies in Media and Communication, 4(1), pp. 30-48.

Knapp, M. L., \& Hall, J. A. (2006). Nonverbal Communication in Human Interaction. Belmont, CA: Thomson Wadsworth.

Knapp, M. L., \& Vangelisti, A. L. (2009). Interpersonal Communication and Human Relationships. Boston, MA: Allyn \& Bacon.

Knobloch, L. K. (2008). Uncertainty reduction theory. In: Baxter, L. A., \& Braithwaite, D. O. (eds.), Engaging Theories in Interpersonal Communication. Multiple Perspectives. London: SAGE.

Koenig Kellas, J. (2008). Narrative theories. In: Baxter, L. A., \& Braithwaite, D. O. (eds.), Engaging Theories in Interpersonal Communication. Multiple Perspectives. London: SAGE.

Krauss, R. M., \& Morsella, E. (2014). Communication and conflict. In: Coleman, P. T., Deutsch, M., \& Marcus, E. C. (eds.), The Handbook of Conflict Resolution. Theory and Practice. San Francisco: Jossey-Bass.

Krcmar, M., Ewoldsen, D. R., \& Koerner, A. (2016). Communication Science Theory and Research. An Advanced Introduction. New York: Routledge.

Littlejohn, S. W., \& Foss, K. A. (2008). Theories of Human Communication. Belmont, CA: Thomson Wadsworth.

Mangion, C. (2011). Philosophical Approaches to Communication. Bristol, UK: Intellect.

Matsumoto, D. (ed.) (2010). APA Handbook of Interpersonal Communication. Washington, DC: American Psychological Association.

Matsumoto, D., \& Hwang, H. S. (2013). Facial expressions. In: Matsumoto, D., Frank, M. G., \& Hwang, H. S. (eds.), Nonverbal Communication. Science and Applications. London: SAGE. http://dx.doi.org/10.4135/9781452244037.n2.

McCrae, R. R., \& Costa, P. T. (2006). Personality in Adulthood. A Five-Factor Theory Perspective. London: The Guilford Press.

Metts, S., \& Planalp, S. (2011). Emotion experience and expression: current trends and future directions in interpersonal relationship research. In: Knapp, M. L., \& Daly, J. A. (eds.), The SAGE Handbook of Interpersonal Communication. Los Angeles: SAGE.

Miller, K. (2002). Communication Theories. Perspectives, Processes, and Contexts. Boston: McGrawHill. 
Miller, K. (2015). Organizational Communication. Approaches and Processes. Stamford, CT: Cengage Learing.

Mongeau, P. A., \& Miller Henningsen, M. L. (2008). Stage theories in relationship development. In: Baxter, L. A., \& Braithwaite, D. O. (eds.), Engaging Theories in Interpersonal Communication. Multiple Perspectives. London: SAGE.

Norman, D. A. (1982). Learning and Memory. San Francisco, CA: W. H. Freeman and Company.

Norman, D. A. (1993). Things That Make Us Smart: Defending Human Attributes in the Age of the Machine. Reading: Addison-Wesley.

Paternotte, C. (2014). Minimal cooperation. Philosophy of the Social Sciences, 44(1), pp. 45-73.

Peirce, C. S. (1992). The Essential Peirce: Selected Philosophical Writings, volume 1, (1867-1893). Kloesel, C. J. W., \& Houser, N. (eds.), Bloomington: Indiana University Press.

Planalp, S. (2001). Communicating Emotion. Social, Moral, and Cultural Processes. Cambridge, UK: Cambridge University Press.

Rogers, E. M. (2003). Diffusion of innovation. New York: Free Press.

Ruesch, J., \& Bateson, G. (1951). Communication. The Social Matrix of Psychiatry. New York: W. W. Norton \& Company.

Salem, P. (2009). The Complexity of Human Communication. Cresskill, NJ: Hampton Press.

Schank, R. C. (1999). Dynamic Memory Revisited. Cambridge, UK: Cambridge University Press.

Searle, J. R. (1969). Speech Acts. Cambridge, UK: Cambridge University Press. http://dx.doi.org/ 10.1017/CBO9781139173438.

Shannon, C. E., \& Weaver, W. (1949). The Mathematical Theory of Communication. Urbana, Ill.: University of Illinois Press.

Shen, L. (2013). Communication as persuasion. In: Cobley, P., \& Schulz, P. J. (eds.), Theories and Models of Communication. Berlin: De Gruyter Mouton.

Solomon, D., \& Theiss, J. (2013). Interpersonal Communication. Putting Theory Into Practice. New York: Routledge.

Sperber, D., \& Wilson, D. (1995). Relevance. Communication \& Cognition. Oxford: Blackwell Publishing.

Tomasello, M. (2003). The Cultural Origins of Human Cognition. Cambridge, MA: Harvard University Press.

Tomasello, M. (2005). Constructing a Language: A Usage-Based Theory of Language Acquisition. Cambridge, Mass.: Harvard Univ. Press.

Tomasello, M. (2008). Origins of Human Communication. Cambridge, MA: MIT Press.

Tomasello, M. (2009). Why We Cooperate. Cambridge: A Boston Review Book.

Watzlawick, P., Beavin Bavelas, J., \& Jackson, D. D. (1967). Pragmatics of Human Communication. New York: W. W. Norton \& Company.

West, R., \& Turner, L. H. (2014). Introducing Communication Theory. Analysis and Application. New York: McGraw-Hill. 